\title{
Anti-Parasite and Cytotoxic Activities of Chloro and Bromo L-Tyrosine Derivatives
}

\author{
Manuel Pastrana Restrepo, ${ }^{a}$ Elkin Galeano Jaramillo, ${ }^{*}, a$ Alejandro Martínez Martínez, ${ }^{a}$ \\ Ana Mesa Arango ${ }^{b}$ and Sara Robledo Restrepo ${ }^{c}$ \\ aProductos Naturales Marinos, Departamento de Farmacia, \\ Facultad de Ciencias Farmacéuticas y Alimentarias, Universidad de Antioquia (UdeA), \\ Calle 70 No. 52-21, Laboratorio 2-131, 050010 Medellín, Colombia \\ ${ }^{b}$ Grupo de Investigación Dermatológica, Facultad de Medicina, Universidad de Antioquia (UdeA), \\ 050010 Medellín, Colombia \\ 'Programa de Estudio y Control de Enfermedades Tropicales (PECET), \\ Facultad de Medicina, Universidad de Antioquia (UdeA), Calle 62 No. 52-59, \\ Laboratorio 632, 050010 Medellín, Colombia
}

\begin{abstract}
A series of twenty-one L-tyrosine derivatives with modifications in the halogenation pattern of the aromatic ring and different degree of methylations on the amine and phenolic hydroxyl groups were synthesized. The structures of all the intermediates and target compounds were confirmed unambiguous by spectroscopy analysis. Additionally, all compounds were evaluated against Plasmodium falciparum and Leishmania panamensis parasites between 20-702 $\mu \mathrm{g} \mathrm{mL}^{-1}$. The cytotoxic evaluation was done to determine the selectivity index for each compound. Six compounds had the lower $\mathrm{EC}_{50}$ (effective concentration 50) against $L$. panamensis. One of these compounds was the most active with an $\mathrm{EC}_{50}$ at $24.13 \mu \mathrm{g} \mathrm{mL}^{-1}(76.07 \mu \mathrm{M})$. All derivatives showed no significant activity against $P$. falciparum and no compound has in vitro antifungal activity at $500 \mu \mathrm{g} \mathrm{mL} \mathrm{m}^{-1}$.
\end{abstract}

Keywords: L. panamensis, P. falciparum, cytotoxic, L-tyrosine

\section{Introduction}

Diseases caused by protozoan parasites affect about one billion people, with a notable incidence in tropical countries. Diseases such as malaria and leishmaniasis are more frequent in developing countries of tropical and subtropical regions. These diseases are endemic problems in Colombia and other Latin American countries.

Currently, malaria is still a common cause of death with approximately 445,000 cases reported in 2016 in tropical countries of Africa, Asia and America; and tragically most of the victims are children under the age of five. ${ }^{1}$ Despite the decrease in fatal cases recorded by the World Health Organization (WHO) in recent years, an increase in the spread of mosquitoes resistant to common insecticides is observed, and more importantly, the emergence of resistance to current drugs by different strains of Plasmodium. ${ }^{2}$ Given that malaria is a disease with global

*e-mail: elkin.galeano@udea.edu.co implications and almost half of the world population is at risk of infection, combating malaria becomes one of the priorities of WHO programs.

On the other hand, leishmaniasis disease affect more than 10 million people worldwide, principally tropical countries. Protozoan parasites of the genus Leishmania responsible for the infection are: L. panamensis, L. braziliensis, L. guyanensis, L. mexicana and L. amazonensis. ${ }^{3}$ Currently, chemotherapies to treat cutaneous leishmaniasis are based on old drugs; unfortunately, all of these drugs have severe toxic effects on patients. Side effects are associated with high therapeutic doses used and long term treatment schemes. ${ }^{4}$ Compounds isolated from marine organisms are considered as rich sources for drug discovery. Marine sponges of Verongida order has a great diversity of bromotyrosine compounds, it has shown anti-parasite activities against T. cruzi, P. falciparum, and L. panamensis protozoa. ${ }^{5-8} \mathrm{We}$ reported isolations and identifications of more than sixteen bromotyrosine isolated from sponges Verongula rigida and Aiolochroia crassa with antiparasitic activity, and we found 
a close relationship between the degree of bromination in the aromatic ring, the methylation in the amino group and their influence in the antiparasitic activity. ${ }^{9}$

Due to the emerging resistance against current drugs, it is mandatory to develop new, safer and more effective antiparasitic agents. For that reason, in the present study, the potentials of marine natural products derivatives compounds, based on bioactive L-bromotyrosines, were evaluated as new antiparasitic compounds. The syntheses of novel chloro and bromo L-tyrosine derivatives, with different grade of methylation of the amino group, lead us to realize a structure-activity relationship between the halogenations patterns in the aromatic ring of the L-tyrosine and the substitution of the amino group, looking for the best structural parameters for the development of new antiparasitic compounds.

\section{Results and Discussion}

\section{Chemistry}

Synthesis of bromo and chloro $N$-substituted derivatives was made using as starting material L-tyrosine. For the synthesis of 21 products, it was necessary to synthesize initially four intermediates, which have their amino and carboxylic acids protected with a carbamate and methyl ester group, respectively. Methyl esters derivatives were formed by the reaction of L-tyrosine with $\mathrm{SOCl}_{2} / \mathrm{MeOH},{ }^{10}$ later the protection of the amino group was done by the reaction with $\mathrm{Boc}_{2} \mathrm{O} /$ triethylamine (TEA) at room temperature. ${ }^{11}$ The bromination and chlorination of the aromatic ring, getting mono and di halogenated compounds, were done using $N$-bromosuccinimide (NBS) and $\mathrm{N}$-chlorosuccinimide (NCS), ${ }^{12}$ producing intermediates (Int1-Int4). These intermediates were divided into two sets, one of them were treated with trifluoracetic acid (TFA) in dichloromethane (DCM) ${ }^{13}$ to cleavage the amino group (1a-1d). The other intermediates were $O$-methylated with MeI in basic media, ${ }^{14}$ and later treated with TFA in DCM (2a-2d) (Scheme 1).

The ${ }^{1} \mathrm{H}$ nuclear magnetic resonance (NMR) analysis of Int1-Int4 shows the presence of a signal at $3.80 \mathrm{ppm}$ (s, 3H) that represents the $-\mathrm{RCOOCH}_{3}$ group of the methyl ester. The signal at $1.40 \mathrm{ppm}(\mathrm{s}, 9 \mathrm{H})$ represents the three-methyl groups of the carbamate moiety. The mono halogenated compounds show in the aromatic region of the spectra three signals that corresponds to the protons at 2, 5, 6 positions in the aromatic ring, while the di halogenated compounds only show in the aromatic region of the spectra one signal, due to the symmetric ring, for two protons at 2 and 6 position.

The syntheses of primary amines were done by the hydrolysis of compounds 1a-1d, 2a-2d with $\mathrm{K}_{2} \mathrm{CO}_{3} / \mathrm{MeOH},{ }^{15}$ getting compounds 4-11. The syntheses of methyl ester tertiary amines were done by the reductive amination of compounds 1a-1d, 2a-2d with formaldehyde/ $\mathrm{NaCNBH}_{3}$, getting compounds 3a-3h. ${ }^{16}$ These set of compounds were divided in two, one of them were treated with $\mathrm{K}_{2} \mathrm{CO}_{3} / \mathrm{MeOH}$ to get the tertiary amines $\mathbf{1 2 - 1 8}$. The other set was treated with $\mathrm{MeI} /$ acetone to get the methyl ester quaternary amines, ${ }^{17}$ which were treated with $\mathrm{K}_{2} \mathrm{CO}_{3} / \mathrm{MeOH}$ to get the quaternary amines 19-24. The synthesis of the primary, tertiary and quaternary amines are shown in Scheme 2 . The ${ }^{1} \mathrm{H}$ NMR analyses of tertiary and quaternary amines show the presence of a signal at $2.88 \mathrm{ppm}(\mathrm{s}, 6 \mathrm{H})$ for the di-methylation of the amino group in the tertiary amines, and $2.97 \mathrm{ppm}(\mathrm{s}, 9 \mathrm{H})$ for the tri-methylation of the amino

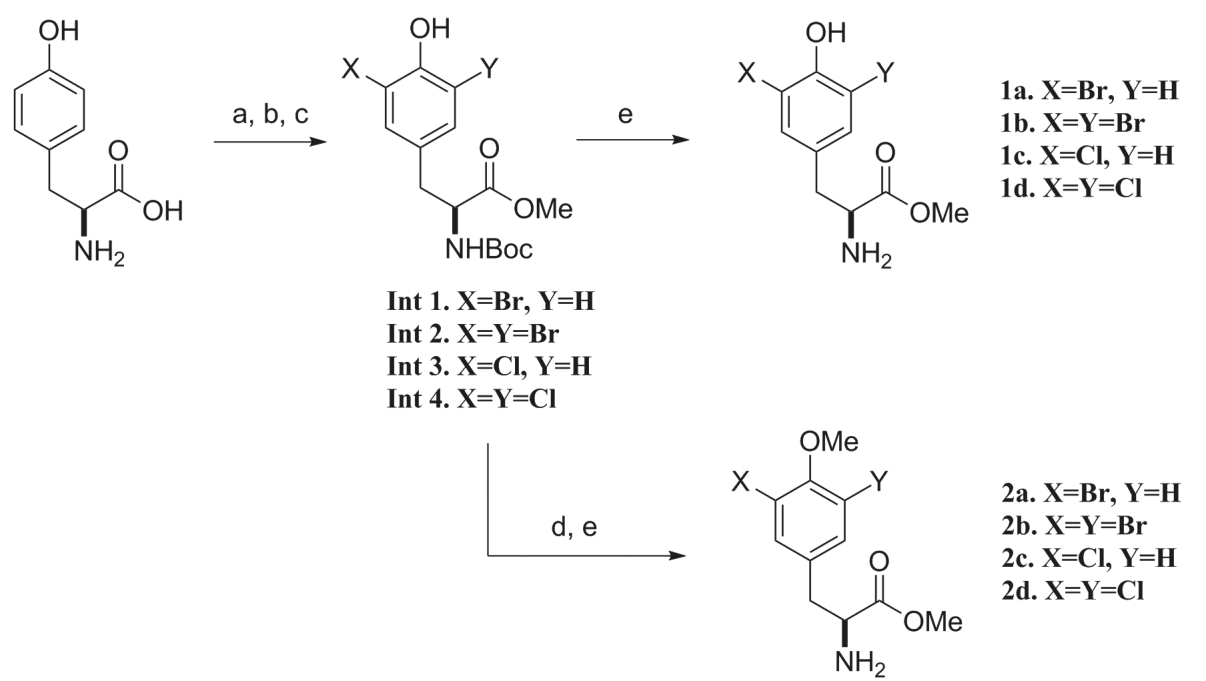

Scheme 1. Intermediate synthesis from L-tyrosine. (a) $\mathrm{SOCl}_{2}, \mathrm{MEOH}$; (b) NBS or NCS, $\mathrm{MeOH}$; (c) $\mathrm{Boc}_{2} \mathrm{O}, \mathrm{TEA}, \mathrm{MeOH}$; (d) $\mathrm{MeI}, \mathrm{K}_{2} \mathrm{CO}$, acetone; (e) TFA, DCM. 
group in the quaternary amines. $O$-Methyl derivatives were confirmed by ${ }^{1} \mathrm{H}$ NMR by the signal at $3.80 \mathrm{ppm}(\mathrm{s}, 3 \mathrm{H})$.

\section{Biological activity}

Compounds were tested against $P$. falciparum (NF54 chloroquine sensitive strain) and L. panamensis (MHOM/ CO/87/UA140epir GP strain) using chloroquine and amphotericin B as positive control drugs, respectively. A cytotoxic test was done over human promonocytic cells (U-937 ATCC CRL1593.2). For every active compound, effective concentration $50\left(\mathrm{EC}_{50}\right)$ and lethal concentration $50\left(\mathrm{LC}_{50}\right)$, in $\mu \mathrm{M}$ units, were tested and selectivity index (SI) was represented as $\mathrm{LC}_{50} / \mathrm{EC}_{50}$. In Table 1, it is shown the anti-leishmanial and antiplasmodial activity of the 21 derivatives.

Compounds 12, 16, 18, 19, 20 and 22 were the most cytotoxic, while compounds 5, 6, 7, 8, 9, 10, 15, 13, 14, 17 and $\mathbf{2 3}$ showed $\mathrm{LC}_{50}$ values higher than $200 \mu \mathrm{M}$, making them potentially safe against mammalian cells U-937.
Compounds 4, 5, 6, 10, 21 and 24 were the most active against $L$. panamensis with values lower than $50 \mu \mathrm{g} \mathrm{mL}^{-1}$. Derivative 21 were the most active with $\mathrm{EC}_{50}$ of $76.07 \mu \mathrm{M}$. Compounds 5 and $\mathbf{6}$ have the higher SI with values of 7.43 and 7.86, respectively. The twenty-one derivatives have no activity against $P$. falciparum.

In this study, it is possible to establish that the type of halogenation, in addition to the degree of methylation on the amino group, have influence in the anti-leishmanial activity of the compounds. Brominated compounds with $O$-methyl substitution in para and primary amine (such as compounds $\mathbf{8}$ and $\mathbf{9}$ ) were less active than their correlated structure with free hydroxyl and additional amine substitutions, compounds $\mathbf{4}$ and $\mathbf{5}$. In general, tertiary and quaternary amines derivatives are less cytotoxic than primary analogs. Mono-chloro compound 6 with $O$-methyl substitution in para and primary amine is the most promising derivative against $L$. panamensis.

Compounds were evaluated at a final concentration of $500 \mu \mathrm{g} \mathrm{mL}^{-1}$ against nineteen fungal strains of medical<smiles>[R]Oc1c([X])cc(C[C@H](N)C(=O)OC)cc1[Y]</smiles>

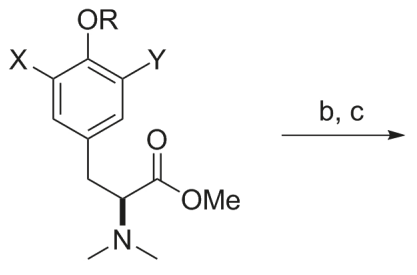

3a. $\mathbf{R}=\mathrm{H}, \mathrm{X}=\mathrm{Br}, \mathrm{Y}=\mathrm{H}$ 3b. $\mathrm{R}=\mathrm{H}, \mathrm{X}=\mathrm{Y}=\mathrm{Br}$ 3c. $\mathrm{R}=\mathrm{H}, \mathrm{X}=\mathrm{Cl}, \mathrm{Y}=\mathrm{H}$ 3d. $\mathrm{R}=\mathrm{H}, \mathrm{X}=\mathrm{Y}=\mathrm{Cl}$ 3e. $\mathrm{R}=\mathrm{Me}, \mathrm{X}=\mathrm{Br}, \mathrm{Y}=\mathrm{H}$ 3f. $\mathrm{R}=\mathrm{Me}, \mathrm{X}=\mathrm{Y}=\mathrm{Br}$ 3g. $\mathrm{R}=\mathrm{Me}, \mathrm{X}=\mathrm{Cl}, \mathrm{Y}=\mathrm{H}$ 3h. $\mathrm{R}=\mathrm{Me}, \mathrm{X}=\mathrm{Y}=\mathrm{Cl}$<smiles>[R]Oc1c([X])cc(CC(C(=O)O)N(C)C)cc1[X]</smiles>

12. $\mathrm{R}=\mathrm{H}, \mathrm{X}=\mathrm{Br}, \mathrm{Y}=\mathrm{H}$

13. $\mathrm{R}=\mathrm{H}, \mathrm{X}=\mathrm{Cl}, \mathrm{Y}=\mathrm{H}$

14. $\mathrm{R}=\mathrm{H}, \mathrm{X}=\mathrm{Y}=\mathrm{Cl}$

15. $\mathrm{R}=\mathrm{Me}, \mathrm{X}=\mathrm{Br}, \mathrm{Y}=\mathrm{H}$

16. $\mathrm{R}=\mathrm{Me}, \mathrm{X}=\mathrm{Y}=\mathrm{Br}$

17. $\mathrm{R}=\mathrm{Me}, \mathrm{X}=\mathrm{Cl}, \mathrm{Y}=\mathrm{H}$

18. $\mathrm{R}=\mathrm{Me}, \mathrm{X}=\mathrm{Y}=\mathrm{Cl}$<smiles>[X]c1cc(CC(C(=O)O)[N+](C)(C)C)cc([X])c1[R]</smiles>

19. $\mathrm{R}=\mathrm{H}, \mathrm{X}=\mathrm{Cl}, \mathrm{Y}=\mathrm{H}$

20. $\mathrm{R}=\mathrm{H}, \mathrm{X}=\mathrm{Y}=\mathrm{Cl}$

21. $\mathrm{R}=\mathrm{Me}, \mathrm{X}=\mathrm{Br}, \mathrm{Y}=\mathrm{H}$

22. $\mathrm{R}=\mathrm{Me}, \mathrm{X}=\mathrm{Y}=\mathrm{Br}$

23. $\mathrm{R}=\mathrm{Me}, \mathrm{X}=\mathrm{Cl}, \mathrm{Y}=\mathrm{H}$

24. $\mathrm{R}=\mathrm{Me}, \mathrm{X}=\mathrm{Y}=\mathrm{Cl}$ 
Table 1. Cytotoxicity, anti-leishmanial and antiplasmodial activities of the L-tyrosine derivatives

\begin{tabular}{|c|c|c|c|c|c|}
\hline \multirow{2}{*}{ Compound } & \multirow{2}{*}{$\frac{\mathrm{U}-937}{\mathrm{LC}_{50}{ }^{\mathrm{a}} /\left(\mu \mathrm{g} \mathrm{mL} \mathrm{m}^{-1}\right)[\mu \mathrm{M}]}$} & \multicolumn{2}{|l|}{ L. panamensis } & \multicolumn{2}{|l|}{ P. falciparum } \\
\hline & & $\mathrm{LC}_{50}{ }^{\mathrm{b}} /\left(\mu \mathrm{g} \mathrm{mL}^{-1}\right)[\mu \mathrm{M}]$ & $\mathrm{SI}^{c}$ & $\mathrm{LC}_{50}{ }^{\mathrm{b}} /\left(\mu \mathrm{g} \mathrm{mL}^{-1}\right)[\mu \mathrm{M}]$ & $\mathrm{SI}^{\mathrm{c}}$ \\
\hline 4 & $>40[153.79]$ & $30.84 \pm 1.06[118.57 \pm 4.07]$ & $>1.29$ & $>20[76.89]$ & $>0.97$ \\
\hline 5 & $265.50 \pm 7.5[783.23 \pm 22.12]$ & $35.73 \pm 5.22[105.40 \pm 15.39]$ & 7.43 & $>20[59.00]$ & 7.51 \\
\hline 6 & $242.23 \pm 8.3[1123.35 \pm 38.49]$ & $30.83 \pm 1.42[142.97 \pm 6.58]$ & 7.86 & $>20[92.20]$ & 8.32 \\
\hline 7 & $>200$ [799.77] & $281.01 \pm 46.20[1123.72 \pm 184.74]$ & $>0.71$ & $270.53 \pm 5.71[1081.81 \pm 22.83]$ & $>4.59$ \\
\hline 12 & $>10[34.70]$ & $69.09 \pm 8.57[239.78 \pm 29.74]$ & $>0.14$ & $>20[69.41]$ & $<0.5$ \\
\hline 13 & $176.8 \pm 26.8[725.54 \pm 109.98]$ & $101.9 \pm 13.10[418.17 \pm 53.75]$ & 1.75 & $89.35 \pm 9.70[366.66 \pm 39.80]$ & 1.97 \\
\hline 14 & $143.2 \pm 15.97[514.86 \pm 57.41]$ & $185.34 \pm 36.86[666.37 \pm 132.52]$ & 0.77 & $>20[71.90]$ & $<7.16$ \\
\hline 19 & $38.53 \pm 1.15[148.92 \pm 4.44]$ & $157.96 \pm 24.35[610.54 \pm 94.11]$ & 0.24 & $>20[77.30]$ & $<1.92$ \\
\hline 20 & $20.49 \pm 1.69[69.89 \pm 5.76]$ & $75.67 \pm 8.57[258.11 \pm 29.23]$ & 0.27 & $>20[68.22]$ & $>1.01$ \\
\hline 8 & $164.03 \pm 12.19[598.40 \pm 44.47]$ & $82.25 \pm 15.46[300.06 \pm 56.40]$ & 1.99 & $>20[72.96]$ & 4.08 \\
\hline 9 & $358.00 \pm 5.6[1014.13 \pm 15.86]$ & $138.59 \pm 36.23[392.59 \pm 102.63]$ & 2.58 & $>20[56.65]$ & 12.07 \\
\hline 10 & $200.85 \pm 10.0[874.55 \pm 43.54]$ & $35.39 \pm 1.74[154.09 \pm 7.57]$ & 5.67 & $>20[87.08]$ & 5.85 \\
\hline 11 & $>40[151.45]$ & $158.42 \pm 34.99[599.84 \pm 132.48]$ & $>0.25$ & $>20[75.72]$ & 0.73 \\
\hline 15 & $270.23 \pm 7.40[894.32 \pm 24.49]$ & $73.40 \pm 11.20[242.91 \pm 37.06]$ & 3.68 & $>20[66.19]$ & 8.60 \\
\hline 16 & $27.90 \pm 1.69[73.21 \pm 4.43]$ & $77.39 \pm 10.61[203.09 \pm 27.84]$ & 0.36 & $702.01 \pm 140.4[1842.25 \pm 368.44]$ & 0.04 \\
\hline 17 & $>200[776.06]$ & $534.31 \pm 77.33[2073.29 \pm 300.06]$ & $>0.37$ & $>20[77.60]$ & $<10$ \\
\hline 18 & $49.16 \pm 4.93[168.26 \pm 16.87]$ & $150.97 \pm 7.98[516.73 \pm 27.31]$ & 0.32 & $>20[68.45]$ & $<2.45$ \\
\hline 21 & $>40[126.10]$ & $24.13 \pm 2.50[76.07 \pm 7.88]$ & $>1.65$ & $>20[63.05]$ & $>1.07$ \\
\hline 22 & $39.16 \pm 1.48[98.86 \pm 3.73]$ & $132.22 \pm 17.27[333.81 \pm 43.06]$ & 0.29 & $>20[50.49]$ & $<1.95$ \\
\hline 23 & $>200[733.27]$ & $148.72 \pm 17.80[545.26 \pm 65.26]$ & $>1.34$ & $>20[73.32]$ & $<10$ \\
\hline 24 & $51.28 \pm 6.85[651.12 \pm 7.56]$ & $28.35 \pm 1.40[92.29 \pm 57.95]$ & $>7.0$ & $>20[65.11]$ & $<10$ \\
\hline Amphotericin B & $37.5 \pm 0.9[40.58 \pm 0.97]$ & $0.06 \pm 0.01[0.0 .6 \pm 0.01]$ & 625 & NA & NA \\
\hline Chloroquine & $152.2 \pm 5.2[475.81 \pm 16.25]$ & NA & NA & $0.84 \pm 0.13[2.62 \pm 0.40]$ & 181 \\
\hline
\end{tabular}

${ }^{\mathrm{a}} \mathrm{LC}_{50}$ : lethal concentration 50; ${ }^{\mathrm{E}} \mathrm{EC}_{50}$ : effective concentration 50; ' $\mathrm{SI}$ : selectivity index $=\mathrm{LC}_{50} / \mathrm{EC}_{50}$. Data represent mean value \pm standard deviation.

interest. No compound showed anti-fungal activity at this concentration.

\section{Conclusions}

The synthesis, cytotoxicity, and activity of twenty-one L-tyrosine derivatives against $L$. panamnesis, $P$. falciparum and 19 fungal strains of medical importance are reported. Compounds 4, 5, 6, 10, 21 and 24 were the most active against $L$. panamensis strain tested. Additionally, compounds 5, 6 and 10 have the higher SI, they were 4 and 6-fold more active than cytotoxic.

Structural simplicity of the compounds, in addition to the high yields in obtaining them, is an advantage for their production to in vivo anti-leishmanial evaluation. This is the first synthetic report for eleven compounds: 12 to $\mathbf{1 5}$ and $\mathbf{1 8}$ to $\mathbf{2 4}$. Most of the tertiary and quaternary amines were synthesized for the first time. Although none of the compounds showed anti-fungal or antiplasmodial activity, this is the first biological evaluation for compounds $\mathbf{8}$ to $\mathbf{2 0}$, $\mathbf{2 3}$ and $\mathbf{2 4}$ against some fungal strains and $P$. falciparum parasite (3D7 strain).

\section{Experimental}

\section{General}

All the laboratory reagents were analytical grade (Sigma-Aldrich). Column chromatography and HPLC solvents were liquid chromatography grade (Merck). Compound purifications were made by column chromatography using Merck silica gel 60 and mixtures of hexane and ethyl acetate. Purifications of biologically tested compounds were made by HPLC Agilent 1200 with diode array detector (DAD, 254, 280 and $366 \mathrm{~nm}$ ) and Eclipse XDB-C18 column using a mixture of $\mathrm{MeOH}$ and $\mathrm{H}_{2} \mathrm{O} 0.1 \%$ formic acid as the mobile phase. ${ }^{1} \mathrm{H}$ and ${ }^{13} \mathrm{C}$ NMR were recorded on Bruker Ultrashield (300 and $75 \mathrm{MHz}$ ) and Ascend III HD (600 and $125 \mathrm{MHz}$ ) with $5 \mathrm{~mm}$ CryoProbe TCI, using $\mathrm{CDCl}_{3}, \mathrm{D}_{2} \mathrm{O}$, and DMSO- $d_{6}$ 
as deuterated solvents. Signals were assigned using two-dimensional heteronuclear correlations (COSY (correlation spectroscopy) and HSQC (heteronuclear single quantum correlation)). High-resolution mass spectra (HRMS) were recorded using electrospray ionization (ESI-MS) in a UPLC-Q-Tof (ultra-performance liquid chromatography quadrupole time of flight) (Xevo-XS-QTof, Waters). The drying and cone gas was nitrogen set to flow rates of $300-30 \mathrm{~L} \mathrm{~h}^{-1}$, respectively. Methanol samples solutions $\left(1 \times 10^{-5} \mathrm{M}\right)$ were directly introduced into the ESI spectrometer at a flow rate of $10 \mu \mathrm{L} \mathrm{min}{ }^{-1}$. A capillary voltage of $3.5 \mathrm{kV}$ was used in the positive scan mode, and the cone voltage (Uc) set to $10 \mathrm{~V}$.

Derivatives synthesis

\section{Synthesis of intermediates (Int1-Int4)}

To $\mathrm{MeOH}(50 \mathrm{~mL})$ at $-5^{\circ} \mathrm{C}$, thionyl chloride $(2190 \mu \mathrm{L}$, $30 \mathrm{mmol}$ ) was dropped slowly to maintain the temperature under $0{ }^{\circ} \mathrm{C}$. Then L-tyrosine $(5000 \mathrm{mg}, 27.6 \mathrm{mmol})$ was added. The resulting mixture was stirred at $80{ }^{\circ} \mathrm{C}$ for $24 \mathrm{~h}$. As the mixture cooled, the product was precipitated by the addition of diethyl ether $(100 \mathrm{~mL})$. The precipitate was collected, washed with ethyl ether $(20 \mathrm{~mL})$ and dried to give L-tyrosine methyl ester hydrochloride. The product was tested by thin layer chromatography (TLC) mobile phase $n$ - $\mathrm{BuOH}: \mathrm{AcOH}: \mathrm{H}_{2} \mathrm{O}$ (4:1:1) showing quantitative conversion. This reaction was done twice. The monobromination of L-tyrosine methyl ester $(2000 \mathrm{mg}$, $8.63 \mathrm{mmol}$ ) was done with NBS (2000 mg, $11.21 \mathrm{mmol}$ ) in $\mathrm{MeOH}(20 \mathrm{~mL})$ stirred at room temperature for $24 \mathrm{~h}$. The solvent was removed, and the crude was partitioned with EtOAc: $\mathrm{H}_{2} \mathrm{O}$. The aqueous phase was recovered and evaporated to get red oil. This crude was tested by TLC mobile phase $n$ - $\mathrm{BuOH}: \mathrm{AcOH}: \mathrm{H}_{2} \mathrm{O}$ (4:1:1) showing the formation of mono bromine compound. This crude was not purified to the next reaction. Compounds dibrominated, monochlorinated and dichlorinated were obtained in the same way using NBS (3380 mg, $19 \mathrm{mmol}$ ), NCS (1500 mg, $11.22 \mathrm{mmol}$ ) and NCS (2535 mg, $19 \mathrm{mmol}$ ), respectively. The protections of the halogenated compounds were done by the reaction in $\mathrm{MeOH}(15 \mathrm{~mL})$ with $\mathrm{Boc}_{2} \mathrm{O}(2300 \mu \mathrm{L}$, $10 \mathrm{mmol})$ and TEA $(2000 \mu \mathrm{L})$ for $24 \mathrm{~h}$ at room temperature. The solvent was removed, the crude was adjusted to $\mathrm{pH}=3$ and later extracted with EtOAc. The organic phase was dried with $\mathrm{Na}_{2} \mathrm{SO}_{4}$ and purified in column chromatography using as mobile phase hexane:EtOAc (3:1).

Methyl (S)-3-(3-bromo-4-hydroxyphenyl)-2-((tert-butoxycarbonyl)-amino) propanoate (Int1)

White solid, $1615 \mathrm{mg}, 2$ stages yield 50\%; ${ }^{1} \mathrm{H}$ NMR $\left(300 \mathrm{MHz}, \mathrm{CDCl}_{3}\right) \delta 7.21$ (d, J $\left.2.0 \mathrm{~Hz}, 1 \mathrm{H}\right), 6.94$ (dd, J 8.3, $2.0 \mathrm{~Hz}, 1 \mathrm{H}), 6.87$ (d, J 8.3 Hz, 1H), 5.07 (d, 1H), 4.51 (d, 1H), $3.71(\mathrm{~s}, 3 \mathrm{H}), 2.97(\mathrm{~m}, 2 \mathrm{H}), 1.41(\mathrm{~s}, 9 \mathrm{H})$.

Methyl (S)-3-(3,5-dibromo-4-hydroxyphenyl)-2-((tert-butoxycarbonyl)-amino) propanoate (Int2)

White solid, $2740 \mathrm{mg}, 2$ stages yield 70\%; ${ }^{1} \mathrm{H}$ NMR (300 MHz, $\left.\mathrm{CDCl}_{3}\right) \delta 7.02(\mathrm{~s}, 2 \mathrm{H}), 5.07(\mathrm{~d}, 1 \mathrm{H}), 4.51(\mathrm{~d}, 1 \mathrm{H})$, 3.73 (s, 3H), 3.13-2.98 (m, 1H), $2.90(\mathrm{~m}, 1 \mathrm{H}), 1.42$ (s, 9H).

Methyl (S)-3-(3-chloro-4-hydroxyphenyl)-2-((tert-butoxycarbonyl)-amino) propanoate (Int3)

White solid, $1565 \mathrm{mg}, 2$ stages yield $55 \%$; ${ }^{1} \mathrm{H}$ NMR $\left(300 \mathrm{MHz}, \mathrm{CDCl}_{3}\right) \delta 7.07(\mathrm{~s}, 1 \mathrm{H}), 6.90(\mathrm{~s}, 2 \mathrm{H}), 5.03$ (s, 1H), 4.51 (s, 1H), 3.71 (s, 3H), 2.96 (s, 2H), 1.41 (s, 9H).

Methyl (S)-3-(3,5-dichloro-4-hydroxyphenyl)-2-((tert-butoxycarbonyl)-amino) propanoate (Int4)

White solid, $1930 \mathrm{mg}, 2$ stages yield $65 \% ;{ }^{1} \mathrm{H}$ NMR $\left(300 \mathrm{MHz}, \mathrm{CDCl}_{3}\right) \delta 7.02(\mathrm{~s}, 2 \mathrm{H}), 5.07(\mathrm{~d}, 1 \mathrm{H}), 4.51(\mathrm{~m}$, $1 \mathrm{H}), 3.73$ (s, 3H), 3.13-2.98 (m, 1H), 2.90 (dd, 1H), 1.42 $(\mathrm{s}, 9 \mathrm{H})$.

\section{Synthesis of compounds 1a-1d}

NHBoc cleavage, Int 1 (1615 mg, $4.31 \mathrm{mmol})$, Int 2 (2740 mg, $6.04 \mathrm{mmol}$ ), Int 3 (1565 mg, $4.74 \mathrm{mmol}$ ) and Int 4 (1930 mg, $5.29 \mathrm{mmol})$ in separate reactions were dissolved in $\operatorname{DCM}(3 \mathrm{~mL})$ at $0{ }^{\circ} \mathrm{C}$. After $5 \mathrm{~min}$, TFA $(1000 \mu \mathrm{L})$ was added to the mixture and left reacting for $24 \mathrm{~h}$ at room temperature. Later the solvents and reagents were evaporated, and the crude of the reaction was adjusted to $\mathrm{pH}=7$. The product was tested by TLC mobile phase hexane:EtOAc (3:1) showing quantitative conversion for Int1-Int4 producing 1180 (1a), 2130 (1b), 1080 (1c) and $1385 \mathrm{mg}$ (1d).

\section{Synthesis of compounds $\mathbf{2 a - 2 d}$}

The $O$-methylations of Int1-Int4 were done by dissolving $1500 \mathrm{mg}$ of each intermediate in acetone with $800 \mathrm{mg} \mathrm{K} \mathrm{CO}_{3}$ and $750 \mu \mathrm{L}$ MeI. The mixture was stirred for $12 \mathrm{~h}$ at room temperature. The solvent was removed and purified in column chromatography using as mobile phase hexane:EtOAc (3:1). The products obtained in the last step were dissolved in DCM (3 mL) at $0{ }^{\circ} \mathrm{C}$. After $5 \mathrm{~min}$, TFA $(1000 \mu \mathrm{L})$ was added to the mixture and left reacting for $24 \mathrm{~h}$ at room temperature. Later the solvents and reagents were evaporated, and the crude of the reaction was adjusted to $\mathrm{pH}=7$. The product was tested by TLC mobile phase hexane:EtOAc $(3: 1)$ showing quantitative conversion for compounds 2a-2d: 2a: $920 \mathrm{mg}$, two steps yield 80\%; 2b: $972 \mathrm{mg}$, two steps yield 80\%; 2c: $885 \mathrm{mg}$, two steps yield $80 \%$; 2d: $916 \mathrm{mg}$, two steps yield $80 \%$. 


\section{Synthesis of compounds $\mathbf{3 a - 3 h}$}

The $N, N$-dimethylation was done by a reductive amination using aqueous formaldehyde at $37 \%$ and $\mathrm{NaCNBH}_{3}$. One equivalent of compounds 1a-1d, 2a-2d were dissolved in $\mathrm{MeOH}(15 \mathrm{~mL}), 2.2$ equivalents of formaldehyde and 1.5 equivalents of $\mathrm{NaCNBH}_{3}$. The reactions were stirred $18 \mathrm{~h}$ at room temperature. Later the solvents were evaporated, the crude reaction partitioned with EtOAc: $\mathrm{H}_{2} \mathrm{O}(50: 50)$ and purified by column chromatography using as a mobile phase EtOAc:hexane (2:1). (3a) 1a (500 mg, $1.82 \mathrm{mmol})$, formaldehyde (300 $\mu \mathrm{L}$, $4 \mathrm{mmol}$ ) and $\mathrm{NaCNBH}_{3}$ (172 mg, $2.73 \mathrm{mmol}$ ); white solid, $383 \mathrm{mg}$, yield 70\%; (3b) 1 b (500 mg, $1.41 \mathrm{mmol}$ ), formaldehyde $(231 \mu \mathrm{L}, 3.1 \mathrm{mmol})$ and $\mathrm{NaCNBH}_{3}$ (133 mg, $2.11 \mathrm{mmol}$ ); white solid, $376 \mathrm{mg}$, yield 70\%; (3c) 1c (500 mg, $2.17 \mathrm{mmol})$, formaldehyde (355 $\mu \mathrm{L}$, $4.8 \mathrm{mmol}$ ) and $\mathrm{NaCNBH}_{3}(133 \mathrm{mg}, 2.04 \mathrm{mmol}$ ); white solid, $390 \mathrm{mg}$, yield 70\%; (3d) 1d (500 mg, $1.89 \mathrm{mmol})$, formaldehyde $(309 \mu \mathrm{L}, 4.15 \mathrm{mmol})$ and $\mathrm{NaCNBH}_{3}$ (178 mg, $2.83 \mathrm{mmol}$ ); white solid, $386 \mathrm{mg}$, yield 70\%; (3e) $2 \mathbf{a}(500 \mathrm{mg}, 1.82 \mathrm{mmol})$, formaldehyde $(300 \mu \mathrm{L}$, $4 \mathrm{mmol})$ and $\mathrm{NaCNBH}_{3}(172 \mathrm{mg}, 2.73 \mathrm{mmol})$; white solid, $383 \mathrm{mg}$, yield 70\%; (3f) 2 b (500 mg, $1.41 \mathrm{mmol}$ ), formaldehyde $(231 \mu \mathrm{L}, 3.1 \mathrm{mmol})$ and $\mathrm{NaCNBH}_{3}(133 \mathrm{mg}$, $2.11 \mathrm{mmol}$ ); white solid, $376 \mathrm{mg}$, yield 70\%; (3g) 2c (500 mg, $2.17 \mathrm{mmol})$, formaldehyde $(355 \mu \mathrm{L}, 4.8 \mathrm{mmol})$ and $\mathrm{NaCNBH}_{3}$ (133 mg, $2.04 \mathrm{mmol}$ ); white solid, $390 \mathrm{mg}$, yield 70\%; (3h) 2d (500 mg, $1.89 \mathrm{mmol}$ ), formaldehyde (309 $\mu \mathrm{L}, 4.15 \mathrm{mmol}$ ) and $\mathrm{NaCNBH}_{3}(178 \mathrm{mg}, 2.83 \mathrm{mmol}$ ); white solid, $386 \mathrm{mg}$, yield $70 \%$.

\section{Primary amines synthesis}

\section{Synthesis of compounds 4-11}

$150 \mathrm{mg}$ of compounds $\mathbf{1 a - 1 d}, \mathbf{2 a - 2 d}$ were dissolved in a mixture of MeOH: $\mathrm{H}_{2} \mathrm{O}: \mathrm{THF}(1: 1: 1)(5 \mathrm{~mL})$ and then $\mathrm{K}_{2} \mathrm{CO}_{3}(100 \mathrm{mg}$ ) was added and the mixture was stirred $24 \mathrm{~h}$ at room temperature. The crude of reaction was adjusted to $\mathrm{pH}=6$. The compounds were tested by TLC mobile phase $n$-BuOH:AcOH: $\mathrm{H}_{2} \mathrm{O}$ (4:1:1) showing quantitative conversion. The final products (4-11) were purified with reversed phase (RP)-HPLC using as a mobile phase a mixture of $\mathrm{MeOH}\left(0.01 \%\right.$ formic acid (F.A.)) and $\mathrm{H}_{2} \mathrm{O}$ (0.01\% F.A.).

\section{(S)-2-Amino-3-(3-bromo-4-hydroxyphenyl)-propanoic acid} (4)

White solid, $140 \mathrm{mg}$, yield 100; ${ }^{1} \mathrm{H}$ NMR $(300 \mathrm{MHz}$, $\left.\mathrm{D}_{2} \mathrm{O}, \mathrm{DMSO}-d_{6}\right) \delta 7.32(\mathrm{~d}, J 1.9 \mathrm{~Hz}, 1 \mathrm{H}), 7.00(\mathrm{dd}, J 8.4$, $1.9 \mathrm{~Hz}, 1 \mathrm{H}), 6.83(\mathrm{~d}, J 8.3 \mathrm{~Hz}, 1 \mathrm{H}), 4.05(\mathrm{~m}, 1 \mathrm{H}), 3.00(\mathrm{~m}$, $2 \mathrm{H}) ;{ }^{13} \mathrm{C}$ NMR $\left(75 \mathrm{MHz}, \mathrm{D}_{2} \mathrm{O}, \mathrm{DMSO}-d_{6}\right) \delta 172.62,153.82$,
135.45, 131.59, 128.96, 118.34, 111.24, 55.50, 35.94; $[\alpha]_{\mathrm{D}}^{25}-12.2$; ESI-Q-Tof-HRMS, $m / z$ : calcd. for $\mathrm{C}_{9} \mathrm{H}_{11} \mathrm{NO}_{3} \mathrm{Br}$ $[\mathrm{M}+\mathrm{H}]^{+}$259.9922, found 259.9915.

(S)-2-Amino-3-(3,5-dibromo-4-hydroxyphenyl)-propanoic acid (5)

White solid, $144 \mathrm{mg}$, yield 100\%; ${ }^{1} \mathrm{H}$ NMR (300 MHz, $\left.\mathrm{D}_{2} \mathrm{O}, \mathrm{DMSO}-d_{6}\right) \delta 7.32$ (s, 2H), 3.71-3.60 (m, 1H), 2.99 (dd, $1 \mathrm{H}), 2.83(\mathrm{dd}, 1 \mathrm{H}) ;{ }^{13} \mathrm{C}$ NMR $\left(75 \mathrm{MHz}, \mathrm{D}_{2} \mathrm{O}, \mathrm{DMSO}-d_{6}\right)$ $\delta$ 174.18, 150.75, 134.56, 131.54, 112.56, 56.74, 36.12; $[\alpha]_{D}^{25}-15.5$; ESI-Q-Tof-HRMS, $m / z$ : calcd. for $\mathrm{C}_{9} \mathrm{H}_{10} \mathrm{NO}_{3} \mathrm{Br}_{2}$ $[\mathrm{M}+\mathrm{H}]^{+}$337.9043, found 337.9027 .

(S)-2-Amino-3-(3-chloro-4-hydroxyphenyl)-propanoic acid (6)

White solid, $140 \mathrm{mg}$, yield 100\%; ${ }^{1} \mathrm{H}$ NMR (300 MHz, $\left.\mathrm{D}_{2} \mathrm{O}, \mathrm{DMSO}-d_{6}\right) \delta 7.16(\mathrm{~d}, J 2.0 \mathrm{~Hz}, 1 \mathrm{H}), 6.95(\mathrm{dd}$, $J$ 8.4, $2.1 \mathrm{~Hz}, 1 \mathrm{H}), 6.83$ (d, J 8.3 Hz, 1H), 3.70 (dd, 1H), $3.00(\mathrm{dd}, 1 \mathrm{H}), 2.85(\mathrm{dd}, 1 \mathrm{H}) ;{ }^{13} \mathrm{C} \mathrm{NMR}\left(75 \mathrm{MHz}, \mathrm{D}_{2} \mathrm{O}\right.$, DMSO- $\left.d_{6}\right) \delta 174.51,152.46,132.33,130.78,129.64$, 121.77, 118.57, 57.21, 36.66; [ $\alpha]_{\mathrm{D}}^{25}-10.1$; ESI-Q-TofHRMS, $m / z$ : calcd. for $\mathrm{C}_{9} \mathrm{H}_{11} \mathrm{NO}_{3} \mathrm{Cl}[\mathrm{M}+\mathrm{H}]^{+} 216.0427$, found 216.0438 .

(S)-2-Amino-3-(3,5-dichloro-4-hydroxyphenyl)-propanoic acid (7)

White solid, $142 \mathrm{mg}$, yield 100\%; ${ }^{1} \mathrm{H}$ NMR (300 MHz, $\left.\mathrm{D}_{2} \mathrm{O}, \mathrm{DMSO}-d_{6}\right) \delta 7.12(\mathrm{~s}, 2 \mathrm{H}), 3.70(\mathrm{~m}, 1 \mathrm{H}), 3.01(\mathrm{dd}$, $1 \mathrm{H}), 2.84(\mathrm{dd}, 1 \mathrm{H}) ;{ }^{13} \mathrm{C} \mathrm{NMR}\left(75 \mathrm{MHz}, \mathrm{D}_{2} \mathrm{O}, \mathrm{DMSO}-d_{6}\right)$ $\delta$ 174.48, 148.81, 131.00, 129.87, 123.73, 57.01, 36.54; $[\alpha]_{D}^{25}-13.6$; ESI-Q-Tof-HRMS, $m / z$ : calcd. for $\mathrm{C}_{9} \mathrm{H}_{10} \mathrm{NO}_{3} \mathrm{Cl}_{2}$ $[\mathrm{M}+\mathrm{H}]^{+}$250.0038, found 250.0065 .

(S)-2-Amino-3-(3-bromo-4-methoxyphenyl)-propanoic acid (8)

White solid, $142 \mathrm{mg} ;{ }^{1} \mathrm{H}$ NMR $\left(300 \mathrm{MHz}, \mathrm{D}_{2} \mathrm{O}\right.$, DMSO- $\left.d_{6}\right) \delta 7.56(\mathrm{~d}, J 2.1 \mathrm{~Hz}, 1 \mathrm{H}), 7.29(\mathrm{dd}, J 8.5,2.1 \mathrm{~Hz}$, $1 \mathrm{H}), 7.11(\mathrm{~d}, J 8.5 \mathrm{~Hz}, 1 \mathrm{H}), 4.06-3.84(\mathrm{~m}, 4 \mathrm{H}), 3.23$ (dd, $1 \mathrm{H}), 3.07(\mathrm{dd}, 1 \mathrm{H}) ;{ }^{13} \mathrm{C} \mathrm{NMR}\left(75 \mathrm{MHz}, \mathrm{D}_{2} \mathrm{O}, \mathrm{DMSO}-d_{6}\right)$ $\delta$ 164.63, 146.03, 125.30, 121.43, 120.57, 104.57, 102.60, 47.52, 26.64; $[\alpha]_{\mathrm{D}}^{25}-8.4$; ESI-Q-Tof-HRMS, $m / z$ : calcd. for $\mathrm{C}_{10} \mathrm{H}_{13} \mathrm{NO}_{3} \mathrm{Br}[\mathrm{M}+\mathrm{H}]^{+} 274.0079$, found 274.0096 .

(S)-2-Amino-3-(3,5-dibromo-4-methoxyphenyl)-propanoic acid (9)

White solid, $144 \mathrm{mg} ;{ }^{1} \mathrm{H}$ NMR $\left(300 \mathrm{MHz}, \mathrm{D}_{2} \mathrm{O}\right.$, DMSO- $\left.d_{6}\right) \delta 7.59(\mathrm{~s}, 2 \mathrm{H}), 3.97-3.80(\mathrm{~m}, 4 \mathrm{H}), 3.23(\mathrm{dd}$, $1 \mathrm{H}), 3.07(\mathrm{dd}, 1 \mathrm{H}) ;{ }^{13} \mathrm{C}$ NMR $\left(75 \mathrm{MHz}, \mathrm{D}_{2} \mathrm{O}\right.$, DMSO- $\left.d_{6}\right)$ $\delta$ 164.20, 144.24, 126.41, 125.17, 109.32, 52.11, 47.14, 26.65; $[\alpha]_{\mathrm{D}}^{25}-11.1$; ESI-Q-Tof-HRMS, $\mathrm{m} / \mathrm{z}$ : calcd. for $\mathrm{C}_{10} \mathrm{H}_{12} \mathrm{NO}_{3} \mathrm{Br}_{2}[\mathrm{M}+\mathrm{H}]^{+} 351.9184$, found 351.9227 . 
(S)-2-Amino-3-(3-chloro-4-methoxyphenyl)-propanoic acid (10)

White solid, $141 \mathrm{mg} ;{ }^{1} \mathrm{H}$ NMR $\left(300 \mathrm{MHz}, \mathrm{D}_{2} \mathrm{O}\right.$, DMSO- $\left.d_{6}\right) \delta 7.20(\mathrm{~s}, 1 \mathrm{H}), 7.06(\mathrm{~d}, J 8.5 \mathrm{~Hz}, 1 \mathrm{H}), 6.96(\mathrm{~d}$, $J 8.4 \mathrm{~Hz}, 1 \mathrm{H}), 3.73$ (s, 4H), $3.02(\mathrm{dd}, 1 \mathrm{H}), 2.87(\mathrm{dd}, 1 \mathrm{H})$; ${ }^{13} \mathrm{C}$ NMR $\left(75 \mathrm{MHz}, \mathrm{D}_{2} \mathrm{O}\right.$, DMSO- $\left.d_{6}\right) \delta 174.76,155.19$, $132.35,130.89,130.23,123.11,114.77,57.69,57.28$, 36.71; $[\alpha]_{\mathrm{D}}^{25}-9.4$; ESI-Q-Tof-HRMS, $m / z$ : calcd. for $\mathrm{C}_{10} \mathrm{H}_{13} \mathrm{NO}_{3} \mathrm{Cl}[\mathrm{M}+\mathrm{H}]^{+}$230.0584, found 230.0594 .

(S)-2-Amino-3-(3,5-dichloro-4-methoxyphenyl)-propanoic acid (11)

White solid, $142 \mathrm{mg} ;{ }^{1} \mathrm{H}$ NMR $\left(300 \mathrm{MHz}, \mathrm{D}_{2} \mathrm{O}\right.$, DMSO- $\left.d_{6}\right) \delta 7.20(\mathrm{~s}, 2 \mathrm{H}), 3.74(\mathrm{~s}, 4 \mathrm{H}), 3.02(\mathrm{dd}, 1 \mathrm{H}), 2.88$ $(\mathrm{dd}, 1 \mathrm{H}) ;{ }^{13} \mathrm{C}$ NMR $\left(75 \mathrm{MHz}, \mathrm{D}_{2} \mathrm{O}\right.$, DMSO- $\left.d_{6}\right) \delta 174.36$, 152.09, 135.25, 131.48, 130.39, 56.98, 36.82; $[\alpha]_{\mathrm{D}}^{25}-12.2$; ESI-Q-Tof-HRMS, $m / z$ : calcd. for $\mathrm{C}_{10} \mathrm{H}_{12} \mathrm{NO}_{3} \mathrm{Cl}_{2}[\mathrm{M}+\mathrm{H}]^{+}$ 264.0194, found 264.0199.

Tertiary amines

\section{Synthesis of compounds 12-18}

$150 \mathrm{mg}$ of compounds $\mathbf{3 a} \mathbf{a}-\mathbf{3 h}$ (except $\mathbf{3 b}$ ) were dissolved in a mixture of $\mathrm{MeOH}: \mathrm{H}_{2} \mathrm{O}: \mathrm{THF}(1: 1: 1)(5 \mathrm{~mL})$ and then $\mathrm{K}_{2} \mathrm{CO}_{3}(100 \mathrm{mg})$ was added and the mixture was stirred $24 \mathrm{~h}$ at room temperature. The crude of reaction was adjusted to $\mathrm{pH}=6$. The compounds were tested by TLC mobile phase $n-\mathrm{BuOH}: \mathrm{AcOH}: \mathrm{H}_{2} \mathrm{O}$ (4:1:1) showing quantitative conversion. The final products (12-18) were purified with RP-HPLC using as a mobile phase a mixture of $\mathrm{MeOH}$ (0.01\% F.A.) and $\mathrm{H}_{2} \mathrm{O}(0.01 \%$ F.A.).

(S)-3-(3-Bromo-4-hydroxyphenyl)-2-(dimethylamino)propanoic acid (12)

White solid, $108 \mathrm{mg}$, yield 75\%; ${ }^{1} \mathrm{H}$ NMR $(300 \mathrm{MHz}$, $\mathrm{D}_{2} \mathrm{O}$, DMSO- $\left.d_{6}\right) \delta 7.34$ (d, $\left.J 1.8 \mathrm{~Hz}, 1 \mathrm{H}\right), 7.01$ (dd, $J$ 8.4, $1.8 \mathrm{~Hz}, 1 \mathrm{H}), 6.81(\mathrm{~d}, J 8.3 \mathrm{~Hz}, 1 \mathrm{H}), 3.91(\mathrm{~m}, 1 \mathrm{H}), 3.22-3.07$ (m, 1H), $2.92(\mathrm{dd}, 1 \mathrm{H}), 2.80(\mathrm{~s}, 6 \mathrm{H}) ;{ }^{13} \mathrm{C}$ NMR $(75 \mathrm{MHz}$, $\left.\mathrm{D}_{2} \mathrm{O}, \mathrm{DMSO}-d_{6}\right) \delta 171.41,153.65,135.30,131.45$, 129.14, 118.20, 111.05, 71.00, 42.91, 33.52; $[\alpha]_{\mathrm{D}}^{25} 60.3$; ESI-Q-Tof-HRMS, $m / z$ : calcd. for $\mathrm{C}_{11} \mathrm{H}_{15} \mathrm{NO}_{3} \mathrm{Br}[\mathrm{M}+\mathrm{H}]^{+}$ 288.0235, found 288.0243 .

(S)-3-(3-Chloro-4-hydroxyphenyl)-2-(dimethylamino)propanoic acid (13)

White solid, $106 \mathrm{mg}$, yield 75\%; ${ }^{1} \mathrm{H}$ NMR $(300 \mathrm{MHz}$, $\mathrm{D}_{2} \mathrm{O}$, DMSO- $\left.d_{6}\right) \delta 7.16(\mathrm{~s}, 1 \mathrm{H}), 7.03(\mathrm{~d}, 1 \mathrm{H}), 6.90(\mathrm{dd}$, $1 \mathrm{H}), 6.81(\mathrm{~d}, 1 \mathrm{H}), 3.81(\mathrm{~m}, 1 \mathrm{H}), 3.11(\mathrm{dd}, 1 \mathrm{H}), 2.89(\mathrm{dd}$, $1 \mathrm{H}), 2.78(\mathrm{~s}, 6 \mathrm{H}) ;{ }^{13} \mathrm{C}$ NMR $\left(75 \mathrm{MHz}, \mathrm{D}_{2} \mathrm{O}\right.$, DMSO- $\left.d_{6}\right) \delta$ 171.60, 152.45, 131.90, 130.68, 128.70, 121.51, 118.30, 71.60, 43.56, 33.76; $[\alpha]_{\mathrm{D}}^{25}$ 54.9; ESI-Q-Tof-HRMS, $m / z$ : calcd. for $\mathrm{C}_{11} \mathrm{H}_{15} \mathrm{NO}_{3} \mathrm{Cl}[\mathrm{M}+\mathrm{H}]^{+} 244.0740$, found 244.0760.

(S)-3-(3,5-Dichloro-4-hydroxyphenyl)-2-(dimethylamino)propanoic acid (14)

White solid, $106 \mathrm{mg}$, yield 75\%; ${ }^{\mathrm{H}} \mathrm{H}$ NMR $(300 \mathrm{MHz}$, $\mathrm{D}_{2} \mathrm{O}$, DMSO- $\left.d_{6}\right) \delta 7.14(\mathrm{~s}, 2 \mathrm{H}), 4.02(\mathrm{~m}, 1 \mathrm{H}), 3.17(\mathrm{dd}$, $1 \mathrm{H}), 2.94(\mathrm{dd}, 1 \mathrm{H}), 2.82(\mathrm{~s}, 6 \mathrm{H}) ;{ }^{13} \mathrm{C}$ NMR $\left(75 \mathrm{MHz}, \mathrm{D}_{2} \mathrm{O}\right.$, DMSO- $\left.d_{6}\right) \delta 170.64,149.23,131.31,129.16,123.18,69.83$, 43.59, 33.52; $[\alpha]_{\mathrm{D}}^{25} 59.1$; ESI-Q-Tof-HRMS, $m / z$ : calcd. for $\mathrm{C}_{11} \mathrm{H}_{14} \mathrm{NO}_{3} \mathrm{Cl}_{2}[\mathrm{M}+\mathrm{H}]^{+}$278.0351, found 278.0352.

(S)-3-(3-Bromo-4-methoxyphenyl)-2-(dimethylamino)propanoic acid (15)

White solid, $121 \mathrm{mg}$, yield 85\%; ${ }^{1} \mathrm{H}$ NMR $(300 \mathrm{MHz}$, $\mathrm{D}_{2} \mathrm{O}$, DMSO- $\left.d_{6}\right) \delta 7.56(\mathrm{~d}, J 2.0 \mathrm{~Hz}, 1 \mathrm{H}), 7.30(\mathrm{dd}, J 8.5$, $2.1 \mathrm{~Hz}, 1 \mathrm{H}), 7.08(\mathrm{~d}, J 8.5 \mathrm{~Hz}, 1 \mathrm{H}), 3.90(\mathrm{~s}, 3 \mathrm{H}), 3.78(\mathrm{dd}$, $1 \mathrm{H}), 3.25(\mathrm{dd}, 1 \mathrm{H}), 3.10(\mathrm{dd}, 1 \mathrm{H}), 2.93(\mathrm{~s}, 6 \mathrm{H}) ;{ }^{13} \mathrm{C} \mathrm{NMR}$ $\left(75 \mathrm{MHz}, \mathrm{D}_{2} \mathrm{O}\right.$, DMSO- $\left.d_{6}\right) \delta 163.05,145.86,125.11$, 121.23, 120.89, 104.37, 102.46, 63.38, 47.57, 24.00; $[\alpha]_{D}^{25} 53.8$; ESI-Q-Tof-HRMS, $m / z$ : calcd. for $\mathrm{C}_{12} \mathrm{H}_{17} \mathrm{NO}_{3} \mathrm{Br}$ $[\mathrm{M}+\mathrm{H}]^{+}$302.0392, found 302.0398 .

(S)-3-(3,5-Dibromo-4-methoxyphenyl)-2-(dimethylamino)propanoic acid (16)

White solid, $123 \mathrm{mg}$, yield 85\%; ${ }^{1} \mathrm{H}$ NMR (300 MHz, $\left.\mathrm{D}_{2} \mathrm{O}, \mathrm{DMSO}-d_{6}\right) \delta 7.57(\mathrm{~s}, 2 \mathrm{H}), 3.90(\mathrm{~s}, 2 \mathrm{H}), 3.82$ $(\mathrm{dd}, 1 \mathrm{H}), 3.28(\mathrm{~d}, 1 \mathrm{H}), 3.06(\mathrm{dd}, 1 \mathrm{H}), 2.95(\mathrm{~s}, 6 \mathrm{H})$; ${ }^{13} \mathrm{C}$ NMR $\left(75 \mathrm{MHz}, \mathrm{D}_{2} \mathrm{O}\right.$, DMSO- $\left.d_{6}\right) \delta 163.23,157.07$, 125.80, 124.46, 108.54, 63.16, 51.93, 23.48; $[\alpha]_{\mathrm{D}}^{25} 61.0$; ESI-Q-Tof-HRMS, $m / z$ : calcd. for $\mathrm{C}_{12} \mathrm{H}_{16} \mathrm{NO}_{3} \mathrm{Br}_{2}[\mathrm{M}+\mathrm{H}]^{+}$ 379.9497, found 379.9490 .

(S)-3-(3-Chloro-4-methoxyphenyl)-2-(dimethylamino)propanoic acid (17)

White solid, $120 \mathrm{mg}$, yield 85\%; ${ }^{\mathrm{H}} \mathrm{NMR}(300 \mathrm{MHz}$, $\mathrm{D}_{2} \mathrm{O}$, DMSO- $\left.d_{6}\right) \delta 7.20(\mathrm{~s}, 1 \mathrm{H}), 7.05(\mathrm{~s}, 1 \mathrm{H}), 6.94(\mathrm{~s}, 1 \mathrm{H})$, $3.72(\mathrm{~s}, 3 \mathrm{H}), 3.64-3.48(\mathrm{~m}, 1 \mathrm{H}), 3.07(\mathrm{dd}, 1 \mathrm{H}), 2.94-2.80$ $(\mathrm{m}, 1 \mathrm{H}), 2.73(\mathrm{~s}, 6 \mathrm{H}) ;{ }^{13} \mathrm{C}$ NMR $\left(75 \mathrm{MHz}, \mathrm{D}_{2} \mathrm{O}\right.$, DMSO- $\left.d_{6}\right)$ $\delta 173.04,154.61,132.43,130.40,130.32,122.66,114.58$, 73.75, 57.65, 40.25, 34.56; [ $\alpha]_{\mathrm{D}}^{25} 49.8$; ESI-Q-Tof-HRMS, $m / z$ : calcd. for $\mathrm{C}_{12} \mathrm{H}_{17} \mathrm{NO}_{3} \mathrm{Cl}[\mathrm{M}+\mathrm{H}]^{+} 258.0897$, found 258.0898 .

(S)-3-(3,5-Dichloro-4-methoxyphenyl)-2-(dimethylamino)propanoic acid (18)

White solid, $121 \mathrm{mg}$, yield $85 \%$; ${ }^{1} \mathrm{H}$ NMR $(300 \mathrm{MHz}$, $\mathrm{D}_{2} \mathrm{O}$, DMSO- $\left.d_{6}\right) \delta 7.20(\mathrm{~s}, 2 \mathrm{H}), 3.73(\mathrm{~s}, 3 \mathrm{H}), 3.59(\mathrm{dd}, 1 \mathrm{H})$, 3.09 (dd, $1 \mathrm{H}), 2.86(\mathrm{dd}, 1 \mathrm{H}), 2.74(\mathrm{~s}, 6 \mathrm{H}) ;{ }^{13} \mathrm{CNMR}(75 \mathrm{MHz}$, $\mathrm{D}_{2} \mathrm{O}$, DMSO- $\left.d_{6}\right) \delta 172.59,151.90,135.35,131.32,130.21$, 73.03, 62.46, 34.21; [ $\alpha]_{\mathrm{D}}^{25}$ 53.5; ESI-MS $m / z 292.6[\mathrm{M}]^{+}$. 


\section{Quaternary amines}

\section{Synthesis of compounds 19-24}

The quaternization of amine group was done using $150 \mathrm{mg}$ of $\mathbf{3 c}-\mathbf{3 h}$, methyl iodide $(350 \mu \mathrm{L})$ and acetone $(3 \mathrm{~mL})$ at room temperature by $18 \mathrm{~h}$. The solid were filtered, washed with acetone and dried. Later the solids were dissolved in a mixture of $\mathrm{MeOH}: \mathrm{H}_{2} \mathrm{O}$ :THF $(1: 1: 1)(5 \mathrm{~mL})$ and then $\mathrm{K}_{2} \mathrm{CO}_{3}(100 \mathrm{mg}$ ) was added and the mixture was stirred $24 \mathrm{~h}$ at room temperature. The crude of reaction was adjusted to $\mathrm{pH}=6$. The compounds were tested by TLC mobile phase $n$-BuOH:AcOH: $\mathrm{H}_{2} \mathrm{O}$ (4:1:1) showing quantitative conversion. The final products were purified with RP-HPLC using as a mobile phase a mixture of $\mathrm{MeOH}$ (0.01\% F.A.) and $\mathrm{H}_{2} \mathrm{O}(0.01 \%$ F.A.).

(S) - 1 - Carboxy-2-(3-chloro-4-hydroxyphenyl)$N, N, N$-trimethylethan-1-aminium (19)

White solid, $170 \mathrm{mg}$, yield 100\%; ${ }^{1} \mathrm{H}$ NMR (300 MHz, $\left.\mathrm{D}_{2} \mathrm{O}, \mathrm{DMSO}-d_{6}\right) \delta 7.17(\mathrm{~d}, J 1.9 \mathrm{~Hz}, 1 \mathrm{H}), 6.97(\mathrm{dd}, J$ 8.4, $1.9 \mathrm{~Hz}, 1 \mathrm{H}), 6.84$ (d, J 8.4 Hz, 1H), 4.04 (m, 1H), 3.23 (m, $1 \mathrm{H}), 3.18(\mathrm{~s}, 9 \mathrm{H}), 2.94(\mathrm{~m}, 1 \mathrm{H}) ;{ }^{13} \mathrm{C}$ NMR $\left(75 \mathrm{MHz}, \mathrm{D}_{2} \mathrm{O}\right.$, DMSO- $\left.d_{6}\right) \delta 169.9,152.5,132.3,130.9,127.4,121.5$, 118.4, 77.6, 53.7, 32.4; $[\alpha]_{\mathrm{D}}^{25}$ 47.2; ESI-Q-Tof-HRMS, $m / z$ : calcd. for $\mathrm{C}_{12} \mathrm{H}_{17} \mathrm{NO}_{3} \mathrm{Cl}[\mathrm{M}]^{+}$258.0901, found 258.0897.

(S)-1-Carboxy-2-(3,5-dichloro-4-hydroxyphenyl)$\mathrm{N}, \mathrm{N}, \mathrm{N}$-trimethylethan-1-aminium (20)

White solid, $172 \mathrm{mg}$, yield 100\%; ${ }^{1} \mathrm{H}$ NMR (300 MHz, $\left.\mathrm{D}_{2} \mathrm{O}, \mathrm{DMSO}-d_{6}\right) \delta 7.15(\mathrm{~s}, 2 \mathrm{H}), 3.97(\mathrm{~m}, 1 \mathrm{H}), 3.23(\mathrm{dd}$, $1 \mathrm{H}), 3.14(\mathrm{~s}, 9 \mathrm{H}), 2.95(\mathrm{dd}, 1 \mathrm{H}) ;{ }^{13} \mathrm{C} \mathrm{NMR}(75 \mathrm{MHz}$, $\left.\mathrm{D}_{2} \mathrm{O}, \mathrm{DMSO}-d_{6}\right) \delta 169.9,140.0,131.0,128.4,123.9,77.7$, 53.9, 32.4; $[\alpha]_{\mathrm{D}}^{25} 53.1$; ESI-Q-Tof-HRMS, $m / z$ : calcd. for $\mathrm{C}_{12} \mathrm{H}_{16} \mathrm{NO}_{3} \mathrm{Cl}_{2}[\mathrm{M}]^{+}$292.0508, found 292.0507.

(S) - 1-Carboxy-2-(3-bromo-4-methoxyphenyl)$N, N, N$-trimethylethan-1-aminium (21)

White solid, $173 \mathrm{mg}$, yield 100\%; ${ }^{1} \mathrm{H}$ NMR (300 MHz, $\left.\mathrm{D}_{2} \mathrm{O}, \mathrm{DMSO}-d_{6}\right) \delta 7.51(\mathrm{~d}, J 2.0 \mathrm{~Hz}, 1 \mathrm{H}), 7.26(\mathrm{dd}, J 8.5$, $2.1 \mathrm{~Hz}, 1 \mathrm{H}), 7.04$ (d, J $8.5 \mathrm{~Hz}, 1 \mathrm{H}), 3.87$ (s, 3H), 3.80 (m, 1H), 3.28 (s, 9H), 3.24 (dd, 1H), $3.08(\mathrm{dd}, 1 \mathrm{H}) ;{ }^{13} \mathrm{C} \mathrm{NMR}$ $\left(75 \mathrm{MHz}, \mathrm{D}_{2} \mathrm{O}\right.$, DMSO- $\left.d_{6}\right) \delta 161.8,146.4,125.5,121.6$, $120.2,104.6,102.6,71.5,47.8,43.7,23.2$; $[\alpha]_{\mathrm{D}}^{25} 53.7$; ESIQ-Tof-HRMS, $m / z$ : calcd. for $\mathrm{C}_{13} \mathrm{H}_{19} \mathrm{NO}_{3} \mathrm{Br}[\mathrm{M}]^{+} 316.0547$, found 316.0458 .

(S)-1-Carboxy-2-(3,5-dibromo-4-methoxyphenyl)$\mathrm{N}, \mathrm{N}, \mathrm{N}$-trimethylethan-1-aminium (22)

White solid, $168 \mathrm{mg}$, yield 100\%; ${ }^{1} \mathrm{H}$ NMR (300 MHz, $\left.\mathrm{D}_{2} \mathrm{O}, \mathrm{DMSO}-d_{6}\right) \delta 7.59(\mathrm{~s}, 1 \mathrm{H}), 3.93(\mathrm{~s}, 3 \mathrm{H}), 3.85(\mathrm{~m}, 1 \mathrm{H})$, 3.33 (s, 10H), $3.11(\mathrm{dd}, 1 \mathrm{H}) ;{ }^{13} \mathrm{C}$ NMR $\left(75 \mathrm{MHz}, \mathrm{D}_{2} \mathrm{O}\right.$,
DMSO- $\left.d_{6}\right) \delta 170.9,153.8,135.6,135.1,119.0,80.7,62.3$, 53.5, 32.8; $[\alpha]_{\mathrm{D}}^{25}$ 59.3; ESI-Q-Tof-HRMS, $\mathrm{m} / \mathrm{z}$ : calcd. for $\mathrm{C}_{13} \mathrm{H}_{19} \mathrm{NO}_{3} \mathrm{Br}_{2}[\mathrm{M}]^{+}$393.9653, found 393.9701.

(S)-1-Carboxy-2-(3-chloro-4-methoxyphenyl)$\mathrm{N}, \mathrm{N}, \mathrm{N}$-trimethylethan-1-aminium (23)

White solid, $173 \mathrm{mg}$, yield 100\%; ${ }^{1} \mathrm{H}$ NMR (300 MHz, $\left.\mathrm{D}_{2} \mathrm{O}, \mathrm{DMSO}-d_{6}\right) \delta 7.21(\mathrm{~s}, 1 \mathrm{H}), 7.06(\mathrm{~d}, J 8.5 \mathrm{~Hz}, 1 \mathrm{H}), 6.95$ $(\mathrm{d}, J 8.5 \mathrm{~Hz}, 1 \mathrm{H}), 3.71(\mathrm{~s}, 4 \mathrm{H}), 3.13(\mathrm{~s}, 10 \mathrm{H}), 2.93$ (dd, $1 \mathrm{H}) ;{ }^{13} \mathrm{C}$ NMR $\left(75 \mathrm{MHz}, \mathrm{D}_{2} \mathrm{O}, \mathrm{DMSO}-d_{6}\right) \delta 171.5,155.2$, 132.4, 131.0, 129.5, 123.0, 114.7, 80.8, 57.8, 53.7, 33.0; $[\alpha]_{\mathrm{D}}^{25} 51.9$; ESI-Q-Tof-HRMS, $m / z$ : calcd. for $\mathrm{C}_{13} \mathrm{H}_{19} \mathrm{NO}_{3} \mathrm{Cl}$ $[\mathrm{M}]^{+}$272.1053, found 272.1057.

(S) -1-Carboxy-2-(3,5-dichloro-4-methoxyphenyl)$\mathrm{N}, \mathrm{N}, \mathrm{N}$-trimethylethan-1-aminium (24)

White solid, $170 \mathrm{mg}$, yield 100\%; ${ }^{1} \mathrm{H}$ NMR (300 MHz, $\left.\mathrm{D}_{2} \mathrm{O}, \mathrm{DMSO}-d_{6}\right) \delta 7.15(\mathrm{~s}, 2 \mathrm{H}), 3.70(\mathrm{~s}, 3 \mathrm{H}), 3.61(\mathrm{~m}, 1 \mathrm{H})$, 3.09 (s, 10H), $2.90(\mathrm{dd}, 1 \mathrm{H}) ;{ }^{13} \mathrm{C} \mathrm{NMR}\left(75 \mathrm{MHz}, \mathrm{D}_{2} \mathrm{O}\right.$, DMSO- $\left.d_{6}\right) \delta 171.0,151.9,134.5,131.3,130.1,80.7,62.3$, 53.5, 33.0; $[\alpha]_{\mathrm{D}}^{25}$ 54.4; ESI-Q-Tof-HRMS, $\mathrm{m} / z$ : calcd. for $\mathrm{C}_{13} \mathrm{H}_{19} \mathrm{NO}_{3} \mathrm{Cl}_{2}[\mathrm{M}]^{+}$292.0507, found 292.0519.

Compounds were stored at room temperature and prior to the biological evaluations, they were solubilized in $0.5 \%$ DMSO and then, diluted to the appropriate concentration in culture media.

\section{Biological activity assays}

The compounds were subjected to in vitro evaluation for their cytotoxicity, anti-leishmanial, antiplasmodial and anti-fungal activity.

\section{Anti-leishmanial activity assay}

The anti-leishmanial activity of compounds was determined according to the ability of the compound to reduce the infection by L. panamensis parasites. For this, the anti-leishmanial activity was tested on intracellular amastigotes of $L$. panamensis transfected with the green fluorescent protein gene (MHOM/CO/87/UA140-EpiRGFP strain). Briefly, U-937 human cells at a density of $3 \times 10^{5}$ cells $\mathrm{mL}^{-1}$ in Roswell Park Memorial Institute medium (RPMI)-1640 and $0.1 \mu \mathrm{g} \mathrm{mL}^{-1}$ of PMA (phorbol 12-myristate 13-acetate) were dispensed on 24-wells microplate and then infected with stationary phase growing L. panamensis promastigotes in a 15:1 parasites per cell ratio. Plates were incubated at $34{ }^{\circ} \mathrm{C}$ and $5 \% \mathrm{CO}_{2}$ for $3 \mathrm{~h}$ and then the cells were washed twice with phosphate buffer solution (PBS) to eliminate not internalized parasites. Fresh RPMI-1640 was added to each well $(1 \mathrm{~mL})$ and plates 
were incubated again to complete infection. After $24 \mathrm{~h}$ of infection, the RPMI-1640 medium was replaced by fresh culture medium containing each compound at four serial dilutions $\left(50,12.5,3.125\right.$ and $\left.0.78 \mu \mathrm{g} \mathrm{mL}^{-1}\right)$ and plates were then incubated at $37{ }^{\circ} \mathrm{C}$ and $5 \% \mathrm{CO}_{2}$ during $72 \mathrm{~h}$, then, cells were removed from the bottom plate with a trypsin/ ethylenediaminetetraacetic acid disodium salt dihydrate (EDTA) (250 mg) solution. The cells were centrifuged at $1100 \mathrm{rpm}$ during $10 \mathrm{~min}$ at $4{ }^{\circ} \mathrm{C}$, the supernatant was discarded, and cells were washed with $1 \mathrm{~mL}$ of cold PBS and centrifuged at $1100 \mathrm{rpm}$ for $10 \mathrm{~min}$ at $4{ }^{\circ} \mathrm{C}$. Cells were washed two times employing PBS, as previously, and after the last wash, the supernatant was discarded, and cells were suspended in $500 \mu \mathrm{L}$ of PBS. Cells were analyzed by flow cytometry employing a flow cytometer (Cytomics FC 500MPL) reading at 488 (exciting) and $525 \mathrm{~nm}$ (emitting) over an argon laser and counting 10,000 events. Infected cells were determined according to the events for green fluorescence (parasites). Infected cells exposed to control drugs (amphotericin B) were used as a control for antileishmanial activity (positive control), while infected cells incubated in absence of any compound or drug were used as a control for infection (negative control). Nonspecific fluorescence was corrected by subtracting fluorescence of unstained cells. All determinations were performed in triplicate in at least two independent experiments. ${ }^{18,19}$

\section{Antiplasmodial activity assay}

Antiplasmodial activity was evaluated in vitro on asynchronic cultures of P. falciparum (3D7 strain), maintained in standard culture conditions. The effect of each compound over the growth of the parasites was determined by quantification of parasite death, based on the measurement of lactate dehydrogenase (LDH) activity released from the cytosol of damaged cells into the supernatant. Briefly, unsynchronized P. falciparum cultures were adjusted to $0.5 \%$ parasitemia and $1 \%$ hematocrit in RPMI medium enriched with 3\% lipid-rich bovine serum albumin (Albumax II). Then, in each well of a 96-wells plate, $100 \mu \mathrm{L}$ of parasite suspension were dispensed and subsequently exposed against $100 \mu \mathrm{L}$ of four serial dilutions of compounds (100, 25, 6.25 and $\left.1.56 \mu \mathrm{g} \mathrm{mL}^{-1}\right)$. Dilutions were prepared from a stock solution of $1000 \mu \mathrm{g} \mathrm{mL}^{-1}$. Chloroquine (CQ) was used as positive antiplasmodial drug control. Parasites unexposed to any compound were used as a control of both growth and viability (negative control). Plates were incubated for $48 \mathrm{~h}$ at $37{ }^{\circ} \mathrm{C}$ in $\mathrm{N}_{2}(90 \%), \mathrm{CO}_{2}(5 \%)$ and $\mathrm{O}_{2}(5 \%)$ atmosphere. After incubation, plates were harvested, and parasites were subjected to three 20-min freeze-thaw cycles. Meanwhile, $100 \mu \mathrm{L}$ of Malstat reagent $(400 \mu \mathrm{L}$ Triton $\mathrm{X}-100$ in $80 \mathrm{~mL}$ deionized water, $4 \mathrm{~g}$ L-lactate, $1.32 \mathrm{~g}$ Tris buffer and $0.022 \mathrm{~g}$ acetylpyridine adenine dinucleotide in $200 \mathrm{~mL}$ deionized water; $\mathrm{pH} 9.0$ ) and $25 \mu \mathrm{L}$ of NBT/PES solution (0.16 g nitroblue tetrazolium salt and $0.08 \mathrm{~g}$ phenazine ethosulfate in $100 \mathrm{~mL}$ deionized water) were added to each well of a second flat-bottomed 96-well microtiter plate. After freeze-thaw cycles, the culture in each of the wells of the first plate was resuspended by pipetting and $15 \mu \mathrm{L}$ of each well was taken and added to the corresponding well of the second plate (containing Malstat and NBT/PES reagents). After an hour of incubation in the dark, color development of the LDH reaction was monitored colorimetrically in a spectrofluorometer (Varioskan, Thermo) reading at $650 \mathrm{~nm}$. The intensity of color in each experimental condition was registered as optical densities (O.D.). Non-specific absorbance was corrected by subtracting O.D. of the blank. Determinations were done in triplicate in at least two independent experiments. ${ }^{20}$

\section{Antifungal activity}

Antifungal activity was evaluated against 19 fungal strains of medical importance as Candida tropicalis (ATCC 750), C. tropicalis (ATCC 200956), C. lusitaniae (ATCC 2819), C. albicans (ATCC 10231), C. krusei (ATCC 6258), C. glabrata (ATCC 90030), Cryptococcus neoformans (ATCC 90112), and C. gattii (ATCC 10865). In addition, the following clinical isolates and strains of filamentous fungi were included: Sporothrix schenckii (UdeA 7027), S. globosa (UdeA 0002), Fusarium oxysporum (UdeA 8038), F. graminearum (UdeA 6003), F. proliferatum (Micoteca da Universidade do Minho (MUM) 16144), F. verticillioides (MUM 16143), Neoscytalidium dimidiatum (UdeA 8023), Aspergillus flavus (ATCC 204304), A. fumigatus (ATCC 204305), Trichophyton interdigitale (ATCC 24198) and Fusarium oxysporum (ATCC 48112). In vitro antifungal activity of derivatives was determined following the Anti-Fungal Susceptibility Testing Subcommittee of the European Committee on Antibiotic Susceptibility Testing (AFST-EUCAST) reference procedure for yeasts and for filamentous. ${ }^{21}$ The anti-fungal tests were carried out in RPMI buffered at $\mathrm{pH}=7$ with 3-morpholinopropanesulfonic acid (MOPS). Compounds were evaluated at a final concentration of $500 \mu \mathrm{g} \mathrm{mL}^{-1}$. One hundred microliters of each concentration diluted twice were dispensed into 96-well microtitration plates and the same volume of each inoculum at $1.5 \times 10^{5} \mathrm{UFC} \mathrm{mL}^{-1}$ were added. Minimal inhibitory concentration (MIC) was defined as the lowest dilution that resulted in total inhibition of visible growth after 24 or $48 \mathrm{~h}$ incubation at $35{ }^{\circ} \mathrm{C}$ of Candida spp. and Cryptococcus spp., respectively. The MICs for filamentous fungi were determined after $24 \mathrm{~h}$ 
of incubation at $28{ }^{\circ} \mathrm{C}$, except for Sporothrix spp. and T. interdigitale (ATCC 24198), which were incubated for five days. The anti-fungals itraconazole and amphotericin B (Sigma-Aldrich Co.) were included as a positive control at a concentration range of 16 to $1 \mu \mathrm{g} \mathrm{mL}^{-1}$ against $C$. krusei (ATCC 6258), C. parapsilosis (ATCC 22019), A. flavus (ATCC 204304) and A. fumigatus (ATCC 204305).

\section{Cytotoxic activity in human macrophages}

Cytotoxic activity of compounds was assessed based on the viability of U-937 cells determined by the MTT (3-(4,5-dimethylthiazol-2-yl)-2,5-diphenyltetrazolium bromide) method. Shortly, 100,000 cells $\mathrm{mL}^{-1}$ in complete RPMI-1640 and the corresponding concentration of each compound $\left(200,50,12.5,3.125 \mu \mathrm{g} \mathrm{mL}^{-1}\right)$ were incubated at $37^{\circ} \mathrm{C}, 5 \% \mathrm{CO}_{2}$ during $72 \mathrm{~h}$. The effect of each concentration of each compound was determined by adding $10 \mu \mathrm{L}$ well ${ }^{-1}$ of MTT solution $\left(0.5 \mathrm{mg} \mathrm{mL}^{-1}\right)$ and incubating at $37^{\circ} \mathrm{C}$ for $3 \mathrm{~h}$. The reaction was stopped with $100 \mu \mathrm{L}$ of $50 \%$ isopropanol solution with $10 \%$ sodium dodecyl sulfate (SDS) and incubation for $30 \mathrm{~min}$. Cell viability was determined based on the quantity of formazan produced, which was measured with a Bio-Rad ELISA reader set at $570 \mathrm{~nm}$. As a viability control, cultured cells in the absence of extracts were used. Doxorubicin was used as a cytotoxicity control. Nonspecific absorbance was corrected by subtracting absorbance (O.D.) of the blank. Determinations were done in triplicate in at least two independent experiments. ${ }^{18}$

\section{Statistical analysis}

Cytotoxicity was determined according to viability and mortality percentages obtained for each experimental condition (synthesized compounds, amphotericin B, benznidazole, chloroquine and culture medium). Results were expressed as $\mathrm{LC}_{50}$ that corresponds to the concentration necessary to kill $50 \%$ of cells, calculated by Probit analysis (parametric method of linear regression that permits doses-response analysis). ${ }^{22}$ Initially, viability percentages were calculated by equation 1, where the O.D. of control well corresponds to $100 \%$ of viability. In turn, mortality percentage corresponds to $100 \%$ - \% viability.

$\%$ Viability $=\frac{\text { O.D. } \text { exposed cells }}{\text { O.D. control cells }} \times 100$

Then, the percentage of cell growth inhibition was calculated using the equation 2 :

$\%$ Cell growth inhibition $=100 \%-\%$ Viability

The cytotoxicity was graded as high, moderate or low according to $\mathrm{LC}_{50}$ values, as follows: high cytotoxicity when $\mathrm{LC}_{50}<100 \mu \mathrm{g} \mathrm{mL}^{-1}$; moderate cytotoxicity when $\mathrm{LC}_{50}$ is in $100-200 \mu \mathrm{g} \mathrm{mL}^{-1}$ range and low cytotoxicity when $\mathrm{LC}_{50}>200 \mu \mathrm{g} \mathrm{mL} \mathrm{L}^{-1}$.

The antiplasmodial activity of each evaluated compound was evidenced by the reduction of the absorbance (O.D.). Indeed, the viability percentage was calculated by equation 3 :

$\%$ Viability $=\frac{(\text { O.D. of parasites exposed })-(\text { O.D. culture medium })}{(\text { O.D. of parasites unexposed })-(\text { O.D. culture medium })}$

Then, the inhibition growing percentage was calculated according to the following equation 4 :

$\%$ Inhibition $=100-\%$ Viability

Anti-leishmanial activity was determined according to reduction of the median fluorescence intensity (MFI) of infected cells percentages obtained for each experimental condition by the cytometer. The number of parasites for each concentration of tested compound was calculated by equation 5, where the MFI in infected cells in the control well corresponds to $100 \%$ of infection.

\%Infection $=\frac{\text { MIF compounds exposed infected cells }}{\text { MIF compounds non-infected cells }} \times 100$

Then, inhibition percentage was calculated with equation 6 :

$\%$ Inhibition $=100-\%$ Infection

The anti-leishmanial and antiplasmodial activity was graded as high, moderate or low according to the $\mathrm{EC}_{50}$ values, as follows: high activity when $\mathrm{EC}_{50}<25 \mu \mathrm{g} \mathrm{mL}^{-1}$; moderate activity when $\mathrm{EC}_{50}$ is in the $25-50 \mu \mathrm{g} \mathrm{mL}^{-1}$ range and low activity when $\mathrm{EC}_{50}>50 \mu \mathrm{g} \mathrm{mL}^{-1}$.

The selectivity index (SI) was calculated by dividing the cytotoxic activity and the antileishmanial or antitrypanosomal activity $\left(\mathrm{SI}=\mathrm{LC}_{50} / \mathrm{EC}_{50}\right)$.

\section{Supplementary Information}

Supplementary data $\left({ }^{1} \mathrm{H}\right.$ NMR, ${ }^{13} \mathrm{C}$ NMR and ESI-Qtof-HRMS spectra) are available free of charge at http://jbcs.sbq.org.br as PDF file.

\section{Acknowledgments}

The authors would like to thank the Colombian Department of Science, Technology and Innovation (Colciencias, grant CT-695-2014) and the University of Antioquia (CODI, CIQF-176) for their financial support. 


\section{References}

1. http://www.who.int/malaria/en/, accessed on May 22, 2018.

2. Ashley, E. A.; Dhorda, M.; Fairhurst, R. M.; Amaratunga, C.; Lim, P.; Suon, S.; Sreng, S.; Anderson, J. M.; Mao, S.; Sam, B.; Sopha, C.; Chuor, C. M.; Nguon, C.; Sovannaroth, S.; Pukrittayakamee, S.; Jittamala, P.; Chotivanich, K.; Chutasmit, K.; Suchatsoonthorn, C.; Runcharoen, R.; Hien, T. T.; ThuyNhien, N. T.; Thanh, N. V.; Phu, N. H.; Htut, Y.; Han, K.-T.; Aye, K. H.; Mokuolu, O. A.; Olaosebikan, R. R.; Folaranmi, O. O.; Mayxay, M.; Khanthavong, M.; Hongvanthong, B.; Newton, P. N.; Onyamboko, M. A.; Fanello, C. I.; Tshefu, A. K.; Mishra, N.; Valecha, N.; Phyo, A. P.; Nosten, F.; Yi, P.; Tripura, R.; Borrmann, S.; Bashraheil, M.; Peshu, J.; Faiz, M. A.; Ghose, A.; Hossain, M. A.; Samad, R.; Rahman, M. R.; Hasan, M. M.; Islam, A.; Miotto, O.; Amato, R.; MacInnis, B.; Stalker, J.; Kwiatkowski, D. P.; Bozdech, Z.; Jeeyapant, A.; Cheah, P. Y.; Sakulthaew, T.; Chalk, J.; Intharabut, B.; Silamut, K.; Lee, S. J.; Vihokhern, B.; Kunasol, C.; Imwong, M.; Tarning, J.; Taylor, W. J.; Yeung, S.; Woodrow, C. J.; Flegg, J. A.; Das, D.; Smith, J.; Venkatesan, M.; Plowe, C. V.; Stepniewska, K.; Guerin, P. J.; Dondorp, A. M.; Day, N. P.; White, N. J.; N. Engl. J. Med. 2014, 371, 411.

3. Alvar, J.; Vélez, I. D.; Bern, C.; Herrero, M.; Desjeux, P.; Cano, J.; Jannin, J.; de Boer, M.; PLoS One 2012, 7, 5.

4. Oliveira, L. F.; Schubach, A. O.; Martins, M. M.; Passos, S. L.; Oliveira, R. V.; Marzochi, M. C.; Andrade, C. A.; Acta Trop. 2011, 118, 87.

5. Xu, M.; Andrews, K. T.; Birrell, G. W.; Tran, T. L.; Camp, D.; Davis, R. A.; Quinn, R. J.; Bioorg. Med. Chem. Lett. 2011, 21, 846.

6. Yang, X.; Davis, R. A.; Buchanan, M. S.; Duffy, S.; Avery, V. M.; Camp, D.; Quinn, R. J.; J. Nat. Prod. 2010, 73, 985.

7. Gutiérrez, M.; Capson, T. L.; Guzmán, H. M.; González, J.; Ortega-Barría, E.; Quiñoá, E.; Riguera, R.; Pharm. Biol. 2005, 43, 762.

8. Córdoba, R.; Tormo, N. S.; Medarde, A. F.; Plumet, J.; Bioorg. Med. Chem. 2007, 15, 5300.
9. Galeano, E.; Martínez, A.; Thomas, O. P.; Robledo, S.; Munoz, D.; Quim. Nova 2012, 35, 1189.

10. Cao, B.; Xiao, D.; Joullie, M. M.; Org. Lett. 1999, 1, 1799.

11. Rehman, A.; Soni, A.; Naik, K.; Nair, S.; Palle, V. P.; Dastidar, S.; Ray, A.; Alam, M. S.; Salman, M.; Cliffe, I. A.; Sattigeri, V.; Bioorg. Med. Chem. Lett. 2010, 20, 5514.

12. Bovonsombat, P.; Khanthapura, P.; Krause, M. M.; Leykajarakul, J.; Tetrahedron Lett. 2008, 49, 7008.

13. Hulme, A. N.; Rosser, E. M.; Org. Lett. 2002, 4, 265.

14. Liu, N. N.; Zhao, S. M.; Zhao, J. F.; Zeng, G. Z.; Tan, N. H.; Liu, J. P.; Tetrahedron 2014, 70, 6630.

15. Asemave, K.; Anhwange, B.; Ahile, U. J.; FUW Trends Sci. Technol. J. 2018, 2, 521.

16. Raimer, B.; Lindel, T.; Chem. - Eur. J. 2013, 19, 6551.

17. Tars, K.; Leitans, J.; Kazaks, A.; Zelencova, D.; Liepinsh, E.; Kuka, J.; Makrecka, M.; Lola, D.; Andrianovs, V.; Gustina, D.; Grinberga, S.; Liepinsh, E.; Kalvinsh, I.; Dambrova, M.; Loza, E.; Pugovics, O.; J. Med. Chem. 2014, 57, 2213.

18. Taylor, V. M.; Cedeño, D. L.; Muñoz, D. L.; Jones, M. A.; Lash, T. D.; Young, A. M.; Constantino, M. H.; Esposito, N.; Vélez, I. D.; Robledo, S. M.; Antimicrob. Agents Chemother. 2011, 55, 4755.

19. Pulido, S. A.; Muñoz, D. L.; Restrepo, A. M.; Mesa, C. V.; Alzate, J. F.; Vélez, I. D.; Robledo, S. M.; Acta Trop. 2012, 122,36 .

20. Nkhoma, S.; Molyneux, M.; Ward, S.; Am. J. Trop. Med. Hyg. 2007, 76, 1107.

21. ht t p : / / www.eucast.org/as t_of_fungi/ methodsinantifungalsusceptibilitytesting/susceptibility_ testing_of_yeasts/, accessed on May 28, 2018.

22. Finney, D. J.; Statistical Method in Biological Assay; Griffin: London, 1978, p. 508-510.

Submitted: April 5, 2018 Published online: July 16, 2018 